\title{
COMPARAÇÃO DO TEOR DE COMPOSTOS BIOATIVOS ANTES E APÓS A SECAGEM DE RESÍDUO DE ACEROLA EM UM SECADOR DE LEITO FIXO (CAMADA ESPESSA)
} \author{
D I S SILVA ${ }^{1}$, P. M. C. CUNHA ${ }^{1}$, B. M. M. ARAÚJO ${ }^{1}$, M. D. SILVA ${ }^{1}$, G F M V SOUZA $^{1}$,
M. A. S. BARROZO \\ ${ }^{\text {I} U n i v e r s i d a d e ~ F e d e r a l ~ d e ~ U b e r l a ̂ n d i a, ~ D e p a r t a m e n t o ~ d e ~ E n g e n h a r i a ~ Q u i ́ m i c a ~}$ \\ E-mail para contato: disegalen@hotmail.com, masbarrozo@ufu.br
}

\begin{abstract}
RESUMO - O Brasil é um dos três maiores produtores de frutas do mundo e, como consequência, é também um dos maiores produtores de resíduos do processamento dessas frutas. A busca por alternativas para a utilização da matéria orgânica gerada vem crescendo, pois esses resíduos possuem em sua composição vitaminas, minerais e compostos antioxidantes importantes para as funções fisiológicas. Assim, o presente trabalho investigou a secagem do resíduo de acerola em um secador de leito fixo em camada espessa, analisando o efeito das variáveis de processo (temperatura, velocidade do ar e tempo de secagem) sobre as propriedades antioxidantes do resíduo. Para isso, o conteúdo de compostos fenólicos, flavonoides e ácido ascórbico foram quantificados. Através da análise dos resultados observou-se a viabilidade do aproveitamento do resíduo após a secagem, pois valores significativos dos compostos foram obtidos após a secagem nas condições estudadas quando comparados com os valores obtidos para o resíduo in natura.
\end{abstract}

\section{INTRODUÇÃO}

O Brasil é um dos três maiores produtores de frutas do mundo e líder na produção de frutas tropicais. São cerca de 45 milhões de toneladas de frutas por ano, das quais 53\% são destinados ao mercado de frutas processadas. Nesse mercado, $60 \%$ da matéria-prima se tornam polpas e sucos e $40 \%$ são resíduos (NOGUEIRA, 2014). Aproveitar esses resíduos minimiza o desperdício de alimentos e gera uma nova fonte alimentar, de interesse econômico e ambiental. Existem várias estratégias possíveis para o melhor aproveitamento do conteúdo de compostos bioativos das frutas e de seus resíduos. Dentre elas, podemos citar o enriquecimento fenólico por via biotecnológica (CORREIA et al., 2004), obtenção de extratos (OLIVEIRA et al., 2009) ou produção de material desidratado a partir da secagem (SILVA et al., 2013).

A secagem em leito fixo é um processo no qual o leito de partículas permanece estático e o gás de secagem percola o leito transferindo calor para a fase sólida e retirando a água. Ela ocorre em camadas, em função da formação da frente de secagem, que correspondem às regiões de intercâmbio de água entre os sólidos e o ar.. Sendo assim, dependendo da espessura do leito, o produto final pode ser heterogêneo (VILLELA e PERES, 2004). 
O processo de retirada da água do material não consiste em uma simples ação, pois é preciso considerar a variação de nutrientes importantes ao futuro consumidor. Diante disso, o objetivo desse trabalho foi o estudo da secagem de resíduo de acerola em leito fixo, a variação do teor de compostos bioativos (ácido ascórbico, fenólicos e flavonoides) após a secagem e a comparação com os teores do mesmo in natura.

\section{MATERIAIS E MÉTODOS}

\subsection{Material}

O resíduo de acerola utilizado nesse trabalho foi obtido na empresa Frutpres localizada em Presidente Olegário - MG. Após a recepção das amostras, estas foram separados em porções, etiquetadas e posteriormente congeladas em freezer doméstico.

\subsection{Condições de Secagem}

O estudo da secagem em camada espessa foi desenvolvido em um leito fixo construído para esta finalidade (Figura 1) no Laboratório de Sistemas Particulados da Faculdade de Engenharia Química da Universidade Federal de Uberlândia. A unidade experimental utilizada é composta por um soprador do tipo ventilador radial (1) de 7,5 cv, um aquecedor elétrico (2) equipado com um variador de voltagem (3) para ajuste da temperatura ao ar de entrada, um controlador de temperatura, um medidor de vazão do tipo anemômetro de fio quente e o leito fixo (4) composto por: região cônica preenchida com esferas de vidro para a distribuição do ar e zona de secagem, composta de um leito cilíndrico. A zona de secagem apresentava as dimensões de 0,25 $\mathrm{m}$ de diâmetro por 0,6 m de altura. Foi utilizada uma camada de 0,25 $\mathrm{m}$ de resíduo de acerola.

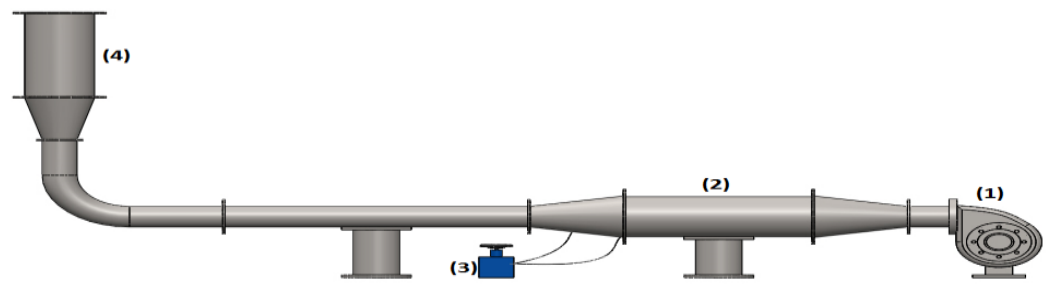

Figura 1 - Esquema da unidade de secagem em leito fixo.

O planejamento experimental utilizado foi o planejamento composto central com 4 repetições no centro (Tabela 1).

Tabela 1 - Níveis do planejamento composto central

\begin{tabular}{cccc}
\hline Níveis & Temperatura $\left({ }^{\circ} \mathbf{C}\right)$ & Velocidade $(\mathbf{m} / \mathbf{s})$ & Tempo de secagem $(\mathbf{m i n})$ \\
\hline $\mathbf{- 1 , 4 1 4}$ & 31,7 & 0,12 & 159,3 \\
$\mathbf{- 1}$ & 40,0 & 0,20 & 180,0 \\
$\mathbf{0}$ & 60,0 & 0,40 & 230,0 \\
$\mathbf{1}$ & 80,0 & 0,60 & 280,0 \\
$\mathbf{+ 1 , 4 1 4}$ & 88,3 & 0,68 & 300,7 \\
\hline
\end{tabular}

Procedimento experimental: Com a unidade experimental montada e os equipamentos de medição devidamente calibrados, o sistema foi ajustado às condições operacionais previamente 


\section{9 a 22 de outubro de 2014 \\ Florianópolis/SC}

estabelecidas pelo planejamento experimental (Tabela 1). Em seguida, foram realizadas medidas de temperatura de bulbo úmido e bulbo seco. Enquanto as condições operacionais se estabilizavam na unidade experimental, o material foi homogeneizado para ser colocado no interior do leito. Depois de atingidas as condições experimentais, o resíduo de acerola era colocado no leito fixo por sua abertura superior formando uma camada de 0,25 m, iniciando neste instante a contagem de tempo do experimento (tempo zero). Foram retiradas amostras aos 20, 40, 100, 160, 220 minutos até o tempo final de cada experimento conforme o planejamento para medida de umidade. As amostragens foram efetuadas ao longo do comprimento do leito nas posições: $0,05,0,10,0,15,0,20$ e $0,25 \mathrm{~m}$. As amostras foram retiradas do interior do leito através de um amostrador do tipo calador duplo adaptado para coletar as amostras nas posições desejadas. Ao final de cada experimento, para avaliação da qualidade, foram retiradas amostras do resíduo de acerola nas posições $0,05,0,15$ e $0,25 \mathrm{~m}$.

\subsection{Umidade}

A umidade das amostras antes e após a secagem foi determinada pelo método gravimétrico em estufa a $105{ }^{\circ} \mathrm{C}$ por 24 horas. Após esse período, as amostras foram retiradas da estufa, colocadas em um dessecador durante aproximadamente $40 \mathrm{~min}$ e, posteriormente, pesadas em balança analítica.

\subsection{Teor de Ácido Ascórbico de Fenólicos Totais e de Flavonoides Totais}

O conteúdo de ácido ascórbico foi determinado por titulometria, método que se baseia na redução do 2,6-diclorofenol-indofenol pelo ácido ascórbico, e os resultados expressos em mg de ácido ascórbico em $100 \mathrm{~g}$ de amostra (base seca) (AOAC, 1995).

O teor de fenólicos totais foi determinado pelo método espectrofotômetro desenvolvido por Folin-Ciocalteu (SINGLETON E ROSSI, 1965). Os resultados foram expressos em $\mathrm{mg}$ equivalente de ácido gálico em $100 \mathrm{~g}$ de amostra (base seca).

O solvente utilizado para a extração dos flavonoides foi o metanol. O conteúdo de flavonoides totais foi determinado pelo método colorimétrico segundo Zhishen et al., (1999). Os resultados foram expressos em $\mu \mathrm{g}$ equivalente de rutina em $100 \mathrm{~g}$ de amostra (base seca).

\subsection{Tratamento Estatístico}

Todas as análises dos compostos antioxidantes foram realizadas em triplicata e os resultados expressos em média \pm desvio padrão (SD). Com o objetivo de analisar os efeitos isolados da temperatura, velocidade do ar de secagem e do tempo de secagem, bem como de interações das três variáveis do processo de secagem na qualidade do resíduo de acerola, optou-se pela metodologia de superfície de resposta.

\section{RESULTADOS E DISCUSSÕES}

\subsection{Secagem}

Na Figura 2 estão apresentados os resultados da secagem (umidade em função do tempo de secagem) do resíduo de acerola em condições experimentais diferentes. 

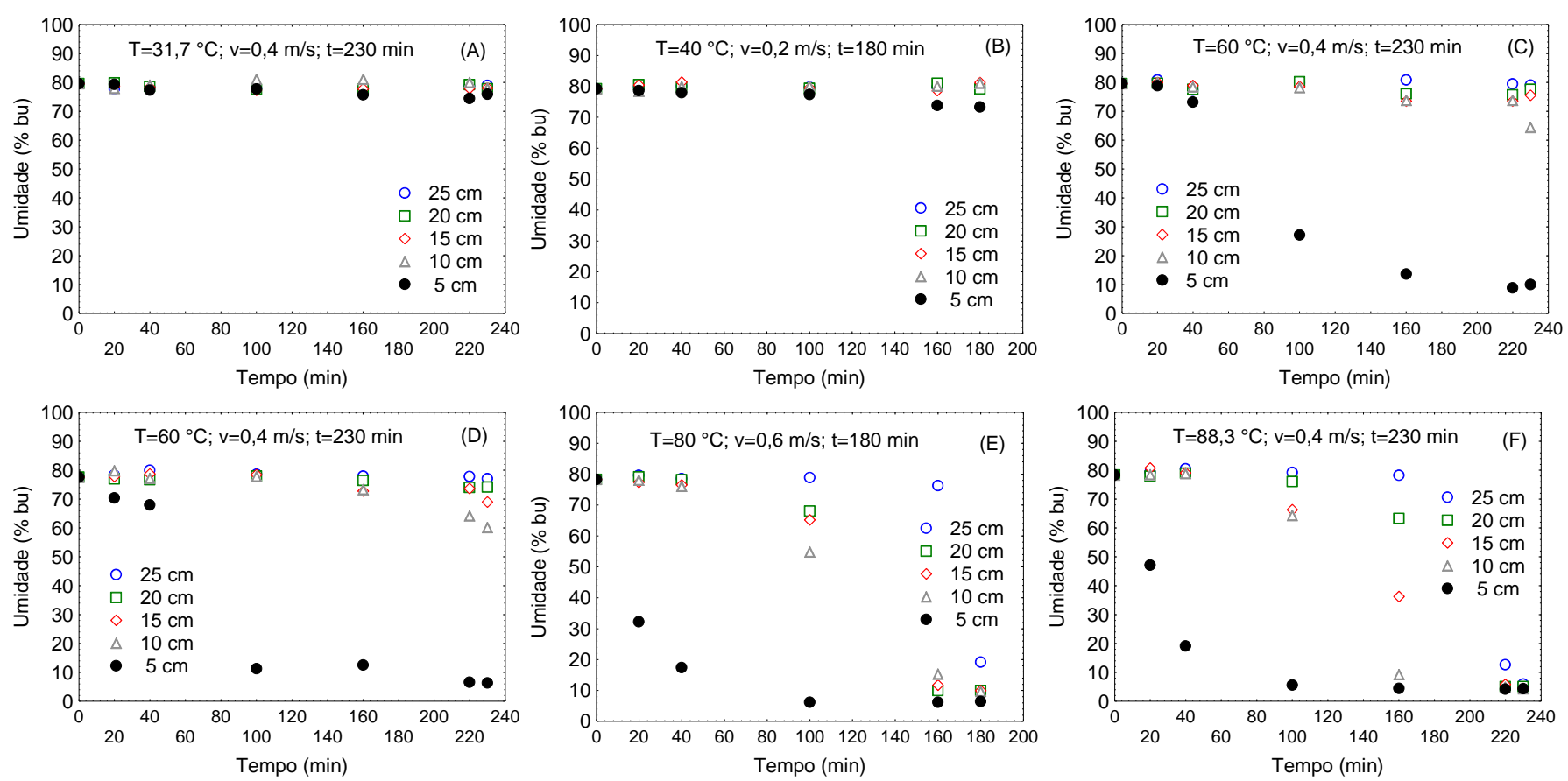

Figura 2 - Perfil de umidade (\% bu) no tempo de secagem do resíduo de acerola em condições experimentais diferentes.

As menores taxas de secagem encontradas em pontos percentuais por hora $\left(\mathrm{pp} . \mathrm{h}^{-1}\right)$ nas respectivas posições axiais do leito $(0,9 ; 0,4 ; 0,4 ; 0,4 ; 0,2)$, foram para o experimento com as condições: $\mathrm{T}=31,7^{\circ} \mathrm{C}, \mathrm{v}=0,4 \mathrm{~m} / \mathrm{s}$ e $\mathrm{t}=230 \mathrm{~min}$ (Figura $2 \mathrm{~A}$ ). Isto ocorre devido a saturação rápida do ar de secagem, devido á baixa vazão de ar deste ensaio. Como esperado, as maiores taxas de secagem $(14,0 ; 22,9 ; 22,8 ; 22,8 ; 19,7)$ foram obtidas nas condições: $\mathrm{T}=80{ }^{\circ} \mathrm{C}, \mathrm{v}=0,6 \mathrm{~m} / \mathrm{s}$ e $\mathrm{t}=180$ min (Figura 2E). A heterogeneidade de secagem no leito foi encontrada em todas as condições experimentais quando comparada a posição axial de 0,5 e $0,25 \mathrm{~m}$, sendo a heterogeneidade maior nos experimentos de condições intermediárias $\left(\mathrm{T}=60{ }^{\circ} \mathrm{C}, \mathrm{v}=0,4 \mathrm{~m} / \mathrm{s}\right.$ e $\mathrm{t}=230 \mathrm{~min}$; Figura 2D) onde as taxas de secagem foram 18,$5 ; 4,5 ; 2,2 ; 0,9 ; 0,1 \mathrm{pp} . \mathrm{h}^{-1}$, respectivamente. Esses valores vão de acordo com Cavariani et al. (1999), que citam que o gradiente de umidade, entre sementes distanciadas desigualmente em relação ao ponto de entrada do ar, é diminuído com reduções da espessura das sementes e com a elevação no fluxo de ar. Portanto a heterogeneidade do produto final deve ser considerada ao definir a espessura final do leito em operações de secagem em leito fixo.

\subsection{Análises Físico-Químicas}

Os alimentos quando submetidos à secagem podem também sofrer alterações físicas, estruturais, mudanças químicas e nutricionais, bem como afetar a qualidade como a cor, textura, sabor, teor de flavonoides totais, entre outros (DI SCALA e CRAPISTE, 2008). Sendo assim, avaliou-se neste trabalho a influência que a temperatura e a velocidade do ar e que o tempo de secagem exercem nos teores de ácido ascórbico, fenólicos totais e flavonoides totais presentes no resíduo de acerola após a secagem. 


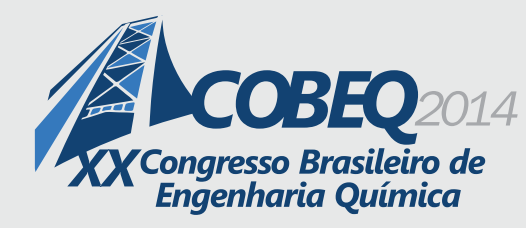

19 a 22 de outubro de 2014

Florianópolis/SC

Os dados obtidos das análises foram tratados estatisticamente e os resíduos foram aleatórios e bem distribuídos. Os coeficientes de determinação para cada análise e em cada posição axial do leito estão apresentados na Tabela 2.

Tabela 2 - Coeficiente de determinação (\%) obtido da análise estatística

\begin{tabular}{cccc}
\hline \multirow{2}{*}{ Análise } & \multicolumn{3}{c}{ Posição Axial do Leito } \\
& $0,05 \mathrm{~m}$ & $0,15 \mathrm{~m}$ & $0,25 \mathrm{~m}$ \\
\hline Ácido Ascórbico & 98,0 & 98,4 & 99,9 \\
Fenólicos Totais & 90,1 & 93,6 & 98,5 \\
Flavonoides Totais & 89,4 & 83,7 & 64,1 \\
\hline
\end{tabular}

Os maiores teores de cada análise realizada variou com a posição do leito em que o resíduo de acerola seco foi coletado, portanto as superfícies de resposta apresentadas nesse trabalho são aquelas em que os teores atingiram os maiores valores. Isto mostra que existe uma hetrogeneidade do produto final. Na Figura 3 estão apresentados os teores de ácido ascórbico em função das variáveis estudadas na posição axial do leito igual a $0,05 \mathrm{~m}$.
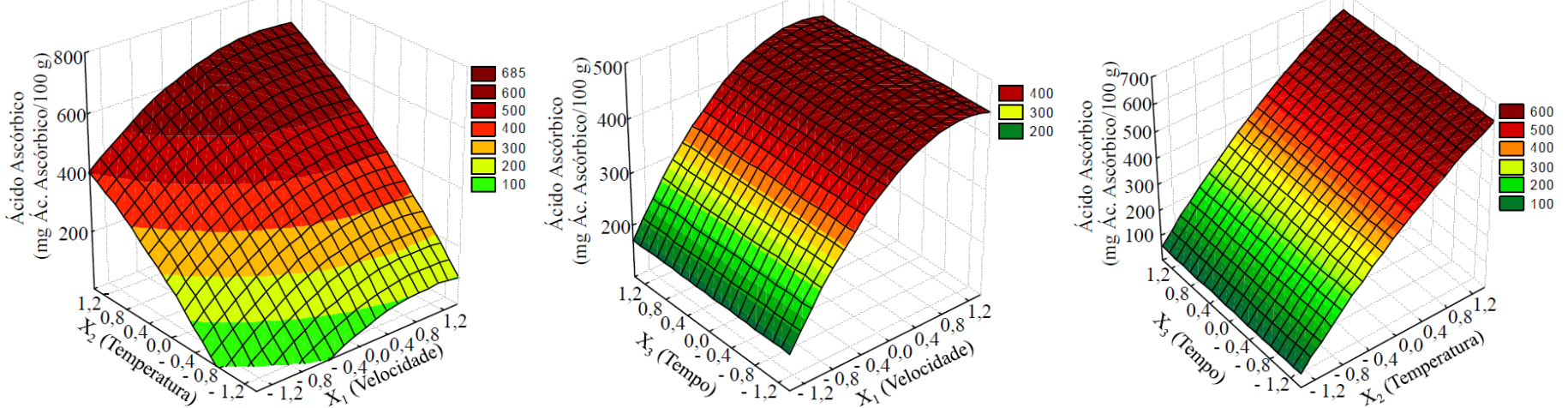

Figura 3 - Superfícies de resposta do teor de ácido ascórbico em função das variáveis estudadas na posição axial do leito de $0,05 \mathrm{~m}$.

O teor de ácido ascórbico do resíduo oriundo do processamento de sucos e polpas in natura foi igual a 21,47 $\pm 1,91 \mathrm{mg}$ ácido ascórbico/100 g e após a secagem seu maior valor foi obtido para as amostras coletadas nas posições axiais do leito iguais a 0,05 m (639,17 £ 40,24 mg ácido ascórbico/100 g) e $0,15 \mathrm{~m}(674,70 \pm 35,11 \mathrm{mg}$ ácido ascórbico/100 g) nas mesmas condições experimentais de secagem $\left(\mathrm{T}=80{ }^{\circ} \mathrm{C}, \mathrm{v}=0,6 \mathrm{~m} / \mathrm{s}\right.$ e $\left.\mathrm{t}=280 \mathrm{~min}\right)$. Observou-se, de uma forma geral, um aumento do teor de ácido ascórbico das amostras coletadas na posição axial igual a $0,05 \mathrm{~m}$ após a secagem (Figura 3) nos valores intermediários e altos das variáveis estudadas neste trabalho. Este comportamento se deve, possivelmente, devido à inativação de certas enzimas responsáveis pela degradação de muitos compostos bioativos (DORTA, LOBO e GONZALEZ, 2012). A posição de $0,05 \mathrm{~m}$ é aquela que tem a maior taxa de secagem, pois o ar está mais quente e seco. Comportamento similar foi encontrado por Ozgur et al., (2011) onde o conteúdo de ácido ascórbico encontrado foi maior em pimentas secas do que em pimentas in natura. Em particular, a vitamina $\mathrm{C}$ (acido ascórbico) é considerada como um indicador de qualidade do alimento processado, devido a sua baixa estabilidade durante os tratamentos térmicos (PODSEDEK, 2007), sendo assim, o método de secagem estudado neste trabalho pode ser considerado 


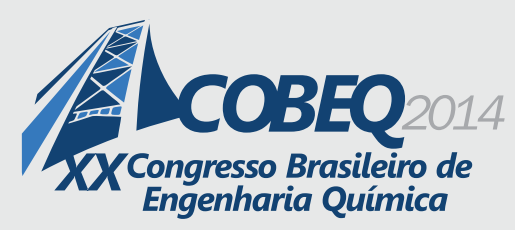

19 a 22 de outubro de 2014
Florianópolis/SC

eficiente, uma vez que o o teor de ácido ascórbico do resíduo de acerola seco foi maior que o mesmo in natura.

As superfícies de resposta dos teores de fenólicos totais em função das variáveis estudadas na posição axial do leito igual a 0,15 m estão apresentadas na Figura 4.
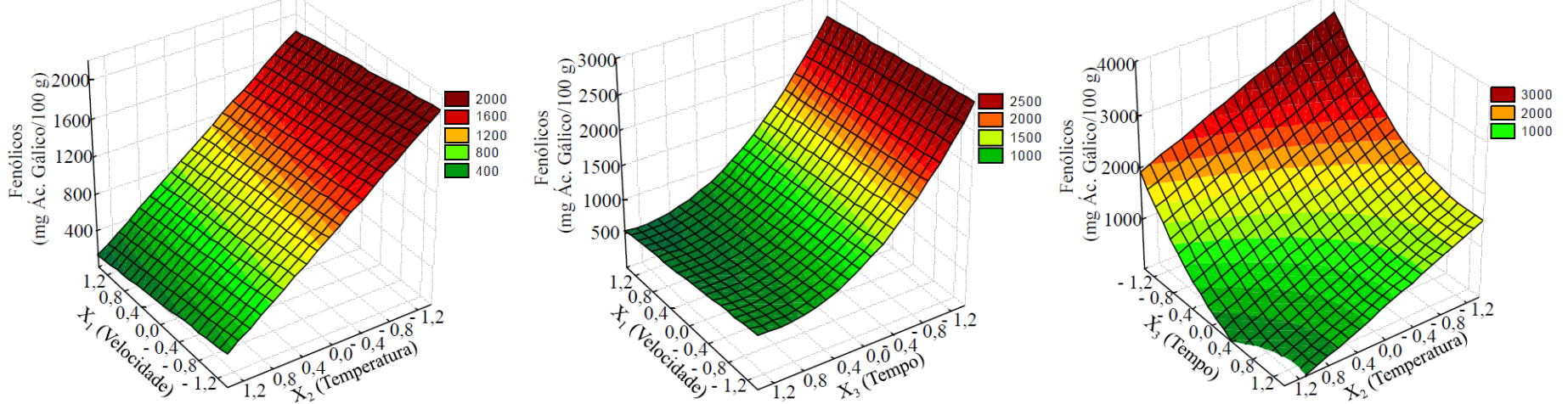

Figura 4 - Superfícies de resposta do teor de fenólicos totais em função das variáveis estudadas na posição axial do leito de $0,15 \mathrm{~m}$.

De forma geral, o teor de fenólicos obtidos para a posição axial do leito igual a $0,15 \mathrm{~m}$ foi maior em baixos níveis de temperatura do ar de secagem e de tempo de secagem. Observa-se também que a velocidade do ar de secagem teve pouca influência dentro do intervalo estudado nesse trabalho. $\mathrm{O}$ teor de fenólicos totais obtido para o resíduo de acerola in natura foi igual a $1425,27 \pm 135,16 \mathrm{mg}$ ácido gálico/100 g e o maior valor obtido do resíduo de acerola seco foi igual a 2845,93 mg ácido gálico/100 g na posição axial do leito de $0,15 \mathrm{~m}$ e na condição de secagem: $\mathrm{T}=60{ }^{\circ} \mathrm{C} ; \mathrm{v}=0,4 \mathrm{~m} / \mathrm{s}$ e $\mathrm{t}=159,3 \mathrm{~min}$. Possivelmente, esse aumento é devido a liberação de compostos fenólicos acumulados nos vacúolos das células que possuem suas fibras rompidas após a secagem (CHISM E HAARD, 1996).

Na Figura 5 estão apresentados os teores de flavonoides totais em função das variáveis estudadas na posição axial do leito igual a $0,15 \mathrm{~m}$.
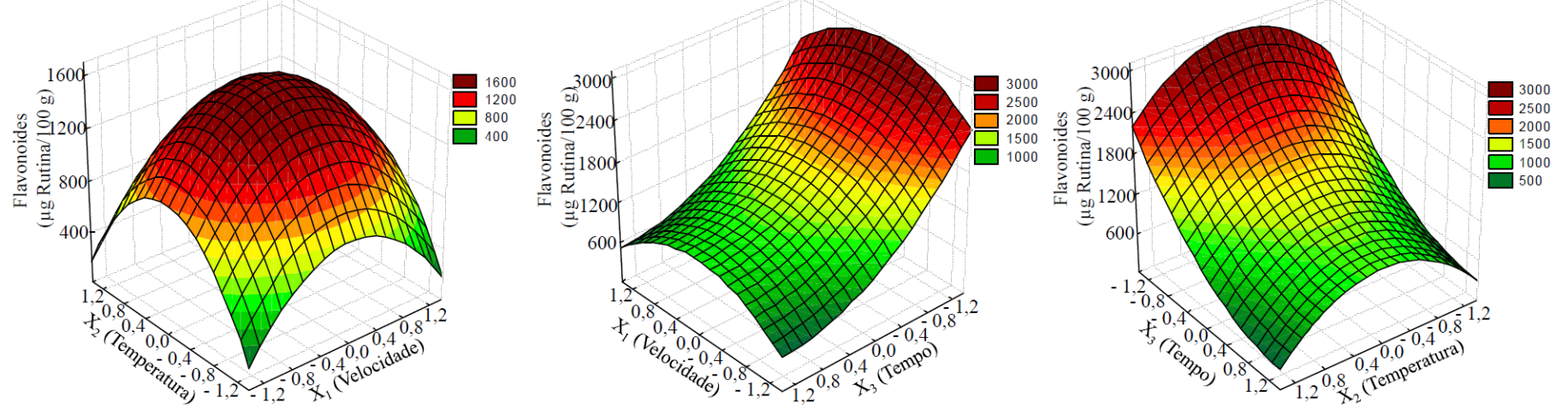

Figura 5 - Superfícies de resposta do teor de flavonoides totais em função das variáveis estudadas na posição axial do leito de $0,15 \mathrm{~m}$. 


\section{9 a 22 de outubro de 2014 \\ Florianópolis/SC}

O teor de flavonoides totais no resíduo de acerola in natura foi igual a 885,00 $\pm 32,46 \mu \mathrm{g}$ rutina/100 g enquanto que para o resíduo de acerola seco o maior teor foi encontrado na posição axial de $0,15 \mathrm{~m}$ do leito $\left(3097,21 \pm 174,97 \mu \mathrm{g}\right.$ rutina/100 g) na condição de secagem: $\mathrm{T}=60{ }^{\circ} \mathrm{C}$; $\mathrm{v}=0,4 \mathrm{~m} / \mathrm{s}$ e $\mathrm{t}=159,3 \mathrm{~min}$. De forma geral, na posição axial de $0,15 \mathrm{~m}$, os maiores teores de flavonoides totais foram obtidos em temperaturas e velocidades intermediárias e em tempos de secagem mínimos dentro do intervalo estudado nesse trabalho. Enfim, a secagem condições intermediárias é favorável. Segundo Stewart et al. 2000, a aplicação de calor pode aumentar o nível de flavonoides livre com o efeito antioxidante. Comportamento similar ao obtido neste tabalho foi encontrado por Chang et al. (2006), em seus estudos com tomates secos, em que o teor de flavonoides das amostras foram superiores aos encontrados nas amostras frescas bem como por Silva et al. (2013) para o resíduo de abacaxi em que os teores de fenólicos e de flavonoides totais foram superiores no resíduo seco quando comparado com os valores obtidos no resíduo in natura. Já para as condições mais drásticas de secagem pode ocorrer degradação térmica.

\section{CONCLUSÃO}

Neste trabalho estudou-se o efeito da secagem de resíduo de acerola em leito fixo no teor de compostos bioativos (ácido ascórbico, fenólicos e flavonoides) após a secagem e a comparação com os teores do resíduo in natura. As três variáveis estudadas influenciaram de forma direta e em conjunto o processo de secagem do resíduo de acerola. Porém, a melhor condição deve ser escolhida levando em consideração a qualidade final do produto. Os melhores resultados para fenólicos totais e para flavonoides totais foram obtidos em temperaturas e velocidades intermediárias e em tempos de secagem baixos. Já no teor de ácido ascórbico os maiores valores encontrados foram em temperaturas, velocidades e tempos de secagem intermediários e elevados. Enfim, a secagem em leito fixo foi eficiente para o aproveitamento de resíduo de acerola, pois foram obtidos altos teores de compostos bioativos que auxiliarão no combate à desnutrição e no combate a doenças diversas. Entretanto, foi observado uma importante heterogeneidade do produto final, que deve ser considerada ao definir a espessura final do leito.

\section{AGRADECIMENTOS}

À Fundação de Amparo à Pesquisa do Estado de Minas Gerais (FAPEMIG) pelos recursos concedidos para esta pesquisa e também no Projeto de Participação Coletiva em Eventos Técnicos-Científicos (PCE-00082-14). À Universidade Federal de Uberlândia e ao CNPq pelo apoio concedido para a execução do projeto. À empresa Frutpres pela doação do resíduo de acerola.

\section{REFERÊNCIAS}

AOAC. Official methods of analysis. Association of Official Analytical Chemists, Gaithersburg, MD., 1995.

CAVARIANI, C.; SILVA, W.R.; MIRANDA, L.C.; NAKAGAWA, J.; BELGIORNO, D.C. Secagem estacionária de sementes de milho com distribuição radial do fluxo do ar. II Andamento físico. Revista Brasileira de Sementes, Brasília, DF, v.21, n. 1, p. 7-17, 1999. 


\section{9 a 22 de outubro de 2014 \\ Florianópolis/SC}

CHANG, C.H., LIN, H.Y., CHANG, C.Y. \& LIU, Y.C. Comparisons on the antioxidant properties of fresh, freeze-dried and hot- air- dried tomatoes. Journal of Food Engineering, 77, 478-485, 2006.

CHISM, G.W. \& HAARD, N.F. Characteristics of edible plant tissues. Food Chemistry. p. 9431011. New York: Marcel Dekker, Inc, 1996.

CORREIA, R. T. P. Production of phenolic antioxidants by the solid-state bioconversion pineapple waste mixed with soy flour using Rhizopusologosporus. Process Biochemistry, v.39, p.2167-2172, 2004.

DI SCALA, K.; CRAPISTE, G., Drying kinetics and quality changes during drying of red pepper. $L W T$, v. 41, p.789-795, 2008.

DORTA,E., LOBO,M.G. \& GONZALEZ,M. Using drying treatments to stabilise mango peel and seed: effect on antioxidant activity. $L W T$, v. 45, p.261-268, 2012.

NOGUEIRA, D. UFU pesquisa reaproveitamento de frutas para minimizar desperdício. Correio de Uberlândia, Cidade e Região. Disponível em: <www.correiodeuberlandia.com.br/cidade-e-regiao/ufu-pesquisa-reaproveitamento-defrutas-para-minimizar-desperdicio-de-alimentos> Acessado em 10 de Abril de 2014.

OLIVEIRA, A. C. Total phenolic content and free radical scavenging activities of methanolic extract powders of tropical fruit residues. Food Chemistry, v. 115, p. 469-475, 2009.

OZGUR, M., OZCAN, T., AKPINAR-BAYIZIT, A. \& YILMAZ-ERSAN, L. Functional compounds and antioxidant properties of dried green and red peppers. African Journal of Agricultural Research, 6, 5638-5644, 2011.

PODSEDEK, A. Natural antioxidant and antioxidant capacity of Brassica vegeta-bles: a review. LWT: Food Science and Technology, v. 40 (1), p.1-11,2007.

SILVA, D. I. S.; NOGUEIRA, G. D. R.; DUZZIONI, A. G. Changes of antioxidante constituents in pineapple (Ananas comosus) residue during process. Industrial Crops and Products SD. p. $557-562,2013$.

SINGLETON,V.L.,ROSSI,J.A. Colorimetry of total phenolics withphosphomolibidic phosphotungistic acid reagents. American Journal of Enology and Viticu, v.16, p,144-158, 1965.

STEWART, A.J., BOZONNET, S., MULLEN, W., JENKINS, G.I., MICHAEL, E.J. \& CROZIER, A.. Occurrence of flavonols in tomatoes and tomato-based products. Journal of Agricultural and Food Chemistry, 48, 2663-2669, 2000.

VILLELA, F.A.; PERES, W.B. Coleta, secagem e beneficiamento de sementes. In. Ferreira, A.G.; Borguetti, R. Germinação: do básico ao aplicado. Porto Alegre: ARTMED, 2004. p. 265-281.

ZHISHEN, J.,MENGCHENG, T.,JIANMING, W. The determination of flavonoid contents in mulberry and their scavenging effects on superoxide radicals. Food Chemistry, v.64, p.555-559, 1999. 